\title{
The Synthesis of a Novel Tröger Base Polymer of 2,6(7)-Diamino-9,9,10,10-tetramethyl-9,10-dihydroanthracene
}

\author{
SADIQ A. KARIM \\ Department of Chemistry, College of Science for Women, University of Babylon, Iraq. \\ ${ }^{*}$ Corresponding author E-mail: sadiqkarim77@ gmail.com \\ http://dx.doi.org/10.13005/ojc/340559
}

(Received: April 29, 2018; Accepted: August 27, 2018)

\begin{abstract}
Condensation polymerisation technique has been employed to synthesise a Novel Tröger base polymer with thermal stability and microporosity. The synthesis process starts with alkylating anthracene, then nitrating and reducing this to produce the monomer. A Tröger base polymer is obtained by polymerising the monomer to afford a white polymer with good solubility into dichloromethane and chloroform, good thermal stability to $\sim 377^{\circ} \mathrm{C}$ and a good BET surface area of $368.6 \mathrm{~m}^{2} / \mathrm{g}$ with a total pore volume of $0.4166 \mathrm{ml} / \mathrm{g}$.
\end{abstract}

Keywords: Tröger Base Polymer, Heterocyclic polymer, Tröger Base Polymer of 2,6(7)-Diamino-9,9,10,10-tetramethyl-9,10-dihydroanthracene.

\section{INTRODUCTION}

The German chemist (Julius Tröger) during his Ph.D., studied, synthesised and isolated (2,8-dimethyl-6H,12H-5,11-methanodibenzo[b,f] $[1,5]$ diazocine) also known as Tröger base 1 from the condensation of methanal (formaldehyde) with 4-aminotoluene ( $p$-toluidine) in an acid-catalysed media. ${ }^{1}$ Through a chemical reaction, 2,8-dimethyl$6 \mathrm{H}, 12 \mathrm{H}-5,11$-methanodibenzo[ $[b, f][1,5]$ diazocine structure $^{2}$ was confirmed by M. A. Spielman and then later by single crystal X-ray diffraction. ${ }^{3}$ After a decade, the Tröger base was described as "fascinating molecules", 4-7 because their structure in which the chiral 1,5-diazocine bridge locks contains two stereogenic nitrogen atoms in its rigid twisted
V-shape, ${ }^{8-10}$ besides the two enantiomers of the Tröger base which exist at room temperature. ${ }^{11-12}$ Some years ago, a patent application was made to prepare Tröger base polymers using aromatic monomers containing diamine with methylene supplier as dimethoxymethane in trifluoroacetic acid. ${ }^{13}$ Subsequently, several Tröger bases synthesised as ladder polymers then tested as potential applications for gas separation membranes ${ }^{14-20}$ or as network polymers. ${ }^{21}$ Furthermore, Tröger base polymers are used in various applications as heterogeneous catalysis. $^{22-24}$ Recently, Tröger base polymer was synthesised by condensation of 2,8-disubstituted Tröger base monomers with certain aromatic compounds. ${ }^{25}$ In this work a Tröger base is prepared for an anthracene derivative after alkylation, nitration

This is an Open Access article licensed under a Creative Commons Attribution-Non Commercial-Share Alike 4.0 International License (https://creativecommons.org/licenses/by-nc-sa/4.0/), which permits unrestricted Non Commercial use, distribution and reproduction in any medium, provided the original work is properly cited. 
and reduction to facilitate the monomer, then the polymerisation of it to form the polymer. This polymer shows good thermal stability and microporosity.

\section{MATERIALS AND METHOD}

\section{Materials and equipment}

Diglyme, $\mathrm{LiAlH}_{4}$ and Raney ${ }^{\circledR}$-Nickel were purchased from Sigma-Aldrich. Anthracene, Hydrazine monohydrate, Dimethoxymethane, Acetonitrile and Potassium nitrate were purchased from Alfa Aesar. Trifluoroacetic acid and Trifluoroacetic anhydride were supplied by Fluorochem.

\section{Equipment used in this research}

Melting points (Mp) were recorded using a Sturat Melting Point SMP10 apparatus. Fourier transform infrared adsorption spectra (FTIR) were recorded in the range $4000-400 \mathrm{~cm}^{-1}$ using an FTIR spectrophotometer as a solid (powder) by Shimadzu IRAffinity-1S. Nuclear Magnetic Resonance (NMR): ${ }^{1} \mathrm{H}$ and ${ }^{13} \mathrm{C}$ and NMR spectra were recorded in a suitable deuterated solvent using Bruker Ascend TM 500 at the School of Chemistry, University of Edinburgh. Mass Spectrometry: Low-resolution mass spectrometric (LRMS) and high-resolution mass spectrometric results (HRMS) were obtained using a Thermo MAT 900 XP, double focusing sector at The University of Edinburgh. Gel Permeation Chromatography (GPC) analyses were performed on chloroform solutions (2 $\left.\mathrm{mg} \mathrm{ml}^{-1}\right)$ using a GPC MAX variable loop equipped with two KF-805L SHODEX columns and a RI(VE3580) detector, operating at a flow rate of $1 \mathrm{ml} \mathrm{min}^{-1}$. Calibration was achieved using Viscotek polystyrene standards (Mw $1000-1,000,000 \mathrm{~g} \mathrm{~mol}^{-1}$ ). BET Surface Areas: Low-temperature $(77 \mathrm{~K})$ nitrogen adsorption/ desorption isotherms were obtained using Coulter SA3100 surface area analyser instruments. Thermogravimetric analyses were performed on a Thermal Analysis SDT Q600 system, heating samples ( 10 $\mathrm{mg}$ ) at a rate of $10^{\circ} \mathrm{C} / \mathrm{min}$. from $50^{\circ} \mathrm{C}$ to $800^{\circ} \mathrm{C}$ under a nitrogen atmosphere.

\section{Procedures}

Synthesis route of 2,6(7)-diamino-9, 9,10,10tetramethyl-9,10-dihydroanthracene-Tröger base polymer (DATMA-TB)

Synthesis of 9, 9,10,10-tetramethyl-9,10dihydroanthracene (TMA)

According to relevant literature ${ }^{26}$, in a nitrogen atmosphere, a mixture of Anthracene
(18.71 g, $105.0 \mathrm{mmol}), \mathrm{LiAlH}_{4}(10.00 \mathrm{~g} 270.30 \mathrm{mmol})$ and diglyme (294.00 ml, $2.07 \mathrm{~mol}$ ) was prepared in a $1 \mathrm{~L}$ round-bottom flask. Then the mixture was refluxed at $150^{\circ} \mathrm{C}$ for $10 \mathrm{~h}$, after which time the reaction was cooled to room temperature and the mixture was poured into $2 \mathrm{~L}(1 \mathrm{~N}) \mathrm{HCl}$ and stirred for 30 minutes. The organic layer was extract by ethyl acetate and recrystallization with ethanol to produce $9,9,10,10$ tetramethyl-9,10-dihydroanthracene $7.50 \mathrm{~g}, 30 \%$ as a white powder; $\mathrm{m} . \mathrm{p}=166-168^{\circ} \mathrm{C}$; FTIR (solid) v $=3055 \mathrm{~cm}^{-1}$ (str. aromatic C-H) , 2972 \& $2963 \mathrm{~cm}^{-1}$ (asy. and sy. str. of $\mathrm{CH}_{3}$ group), $1362 \mathrm{~cm}^{-1}$ (sy. bending of $\left.\mathrm{CH}_{3}\right) ;{ }^{1} \mathrm{H} \mathrm{NMR}\left(500 \mathrm{MHz}, \mathrm{CDCl}_{3}\right) \delta 8.13(\mathrm{~d}, \mathrm{~J}=8.8$ $\mathrm{Hz}, 4 \mathrm{H}, \mathrm{ArH}$ ), 7.70 (d, J = 8.7 Hz, 4H, ArH), 1.76 (s, $\left.12 \mathrm{H}, \mathrm{CH}_{3}\right) ;{ }^{13} \mathrm{C}$ NMR (126 MHz, $\mathrm{CDCl}_{3}$ ) $\delta 142.7$ (Ar), 122.4 (Ar), 121.7 (Ar), 38.5 (quadruple carbon), 34.5 $\left(\mathrm{CH}_{3}\right)$; LRMS (El, $\left.\mathrm{mlz}\right)$ : calculated for $\mathrm{C}_{18} \mathrm{H}_{20} 236.3$, $236.4(\mathrm{M}+)$ found.

\section{Synthesis of 9,9,10,10-tetramethyl-2,6(7)-Dinitro- 9,10-dihydroanthracene (DNTMA)}

A mixture of TMA $(5.00 \mathrm{~g}, 21.15 \mathrm{mmol})$, potassium nitrate $\left(\mathrm{KNO}_{3}\right)$ (4.28 g, $\left.42.30 \mathrm{mmol}\right)$ and Acetonitrile $(250.00 \mathrm{ml})$ was prepared. Then trifluoroacetic anhydride (TFAA) $(35.00 \mathrm{ml}, 52.05 \mathrm{~g}$, and $247.80 \mathrm{mmol}$ ) was added drop-wise. The mixture was then stirred for $24 \mathrm{~h}$, at room temperature, after which a white precipitate had formed. The solvent was removed using a vacuum pump and the residue was stirred with water then extracted with chloroform to produce a yellow solid. This crude product was subjected to column chromatography (eluent: Chloroform) to produce 9,9,10,10-tetramethyl-2,6(7)Dinitro-9,10-dihydroanthracene (DNTMA) $4.20 \mathrm{~g}$, $60 \%$ as an off-white; $m . p=236-238^{\circ} \mathrm{C}$; FTIR (solid) $v$ $=1516$ and $1346 \mathrm{~cm}^{-1}$ for asymmetric and symmetric for $\mathrm{NO}_{2}$ group; ${ }^{1} \mathrm{H}$ NMR (500 MHz, $\mathrm{CDCl}_{3}$ ) $\delta 8.13$ (d, J = 8.8 Hz, 2H, ArH), $7.71(\mathrm{~d}, \mathrm{~J}=8.8 \mathrm{~Hz}, 2 \mathrm{H}$, ArH), 7.69 (s, 2H, ArH), $1.76\left(\mathrm{~s}, 12 \mathrm{H}, \mathrm{CH}_{3}\right) ;{ }^{13} \mathrm{C} \mathrm{NMR}$ $\left(126 \mathrm{MHz}, \mathrm{CDCl}_{3}\right.$ ) $\delta 148.0(\mathrm{Ar}), 147.0(\mathrm{Ar}), 128.4(\mathrm{Ar})$, 126.8 (Ar), 122.4 (Ar), 121.6 (Ar), 38.5 (quadruple carbon), $34.7\left(\mathrm{CH}_{3}\right)$; HRMs (El, $\left.\mathrm{mlz}\right)$ : Calculated for $\mathrm{C}_{19} \mathrm{H}_{22} \mathrm{~N}_{2} \mathrm{O}_{4}$ 326.40: $326.2950(\mathrm{M}+)$ found.

\section{Synthesis of 2,6(7)-Diamino-9,9,10,10-tetramethyl -9,10-dihydroanthracene (DATMA) \\ A suspension of 2,6(7)-Diamino-9,9,10,10-} tetramethyl-9,10-dihydroanthracene (DNTMA) (5.00 $\mathrm{g}, 15.32 \mathrm{mmol})$ in THF $(200 \mathrm{ml})$ was stirred for $30 \mathrm{~min}$. in a nitrogen atmosphere. Then Raney Nickel (40 mg) was added to the mixture. Hydrazine 
monohydrate $(13.00 \mathrm{~g}, 259.69 \mathrm{mmol})$ was added drop-wise and the mixture was refluxed for 24 hours. The colourless mixture was cooled in an ice bath and filtered in nitrogen. The organic layer was extracted with diethyl ether and the solvent was removed in a vacuum at $25^{\circ} \mathrm{C}$ to produce 2,6(7)-Diamino9,9,10,10-tetramethyl-9,10-dihydroanthracene $3.1 \mathrm{~g}, 90 \%$ as a white powder; m.p $=202-205^{\circ} \mathrm{C}$; FTIR solid $v=3340 \& 3309 \mathrm{~cm}^{-1}$ for asy. \& sy. of $\mathrm{NH}_{2}$ group, $1620 \mathrm{~cm}^{-1}$ bending vibration of $\mathrm{NH}_{2}$ group; ${ }^{1} \mathrm{H}$ NMR $\left(500 \mathrm{MHz}, \mathrm{CDCl}_{3}\right) \delta 7.31(\mathrm{~d}, \mathrm{~J}=3.2 \mathrm{~Hz}$, $2 \mathrm{H}, \mathrm{Ar}), 7.29$ (d, J = 3.2 Hz, 2H, Ar), 6.80 (s, 2H, Ar), 3.59 (s, $\left.4 \mathrm{H}, \mathrm{NH}_{2}\right), 2.17\left(\mathrm{~s}, 12 \mathrm{H}, \mathrm{CH}_{3}\right) ;{ }^{13} \mathrm{C} \mathrm{NMR}$ (126 MHz, $\mathrm{CDCl}_{3}$ ) 145.3 (Ar), 143.1 (Ar), $128.2(\mathrm{Ar})$, 119.0 (Ar), 114.8 (Ar), 113.0 (Ar), 37.1 (quadruple carbon), $35.4\left(\mathrm{CH}_{3}\right)$; HRMs (El, $\left.\mathrm{mlz}\right)$ : Calculated for $\mathrm{C}_{19} \mathrm{H}_{26} \mathrm{~N}_{2}$ 282.4300: $266.2987(\mathrm{M}+)$ found.

\section{Synthesis of 2,6(7)-Diamino-9,9,10,10-tetramethyl -9,10-dihydroanthracene-Tröger base polymer (DATMA-TB)}

9,9,10,10-Tetramethyl-2,6(7)-diamino-9,10dihydroanthracene (DATMA) $(1 \mathrm{~g}, 3.76 \mathrm{mmol})$ was dissolved in dimethoxymethane (DMM) $(2 \mathrm{ml}, 1.72 \mathrm{~g}$, $23.24 \mathrm{mmol}$ ). The solution was cooled in an ice bath and trifluoroacetic acid $(10 \mathrm{ml})$ was added drop-wise for $10 \mathrm{~min}$. and the mixture was stirred for 7 days at room temperature. The viscous mixture was slowly poured into $25 \mathrm{ml}$ of aqueous ammonium hydroxide solution and stirred vigorously for $2 \mathrm{~h}$, during which a solid was formed. The solid was collected by filtration, washed with water and methanol until the washed liquids ran clear. The resulting powder was dissolved in chloroform and re-precipitated with methanol three times and then dissolved in chloroform. The solution was added drop-wise into hexane with vigorous stirring. The polymer was collected by filtration, as a fine powder. The polymer was dried in a vacuum oven at $120^{\circ} \mathrm{C}$ for $5 \mathrm{~h}$, to produce $0.84 \mathrm{~g}, 70 \%$ as an off-white powder; FTIR (solid) (Fig. 1) $v=3055 \mathrm{~cm}^{-1}$ (Ar-H), $2943 \mathrm{~cm}^{-1}$ (asy. str. $\mathrm{CH}_{3}$ ), $2963 \mathrm{~cm}^{-1}$ (asy. \& sy. str. of $\mathrm{CH}_{2} \& \mathrm{CH}_{3}$ groups), $2860 \mathrm{~cm}^{-1}$ (sy. str. of $\mathrm{CH}_{2}$ group), 1680 , 1597 and $1489 \mathrm{~cm}^{-1}(\mathrm{C}=\mathrm{C}$ of $\mathrm{Ar}), 1325 \mathrm{~cm}^{-1}(\mathrm{Ar}-\mathrm{N})$, $1215 \mathrm{~cm}^{-1}\left(\mathrm{C}_{\text {aliphatic }}-\mathrm{N}\right) ;{ }^{1} \mathrm{H}$ NMR $\left(500 \mathrm{MHz}, \mathrm{CDCl}_{3}\right)$ (Fig. 2). $\delta 7.89$ (br. m, $4 \mathrm{H}, \mathrm{Ar}$ ), 4.48 (br. d, J $=17.0$ $\mathrm{Hz}, 2 \mathrm{H}$, aliphatic), 4.27 (br. s, 2H, aliphatic), 3.90 (br. d, J = $17.0 \mathrm{~Hz}, 2 \mathrm{H}$, aliphatic), 1.73 (br. s, $12 \mathrm{H}$, $\left.\mathrm{CH}_{3}\right) ;{ }^{13} \mathrm{C}$ NMR (126 MHz, $\mathrm{CDCl}_{3}$ ) (Fig. 3). $\delta 146.9$ (Ar), 144.5 (Ar), 141.2 (Ar), 132.5 (Ar), 131.4 (Ar), 127.9 (Ar), 126.6 (Ar), 126.4 (Ar), 125.9 (Ar), 67.4 (aliphatic), 64.24 (aliphatic), 55.0 (aliphatic), 17.4 $\left(\mathrm{CH}_{3}\right)$. On a BET surface area (Fig. 4), the sample was degassed overnight before analysis to give a value of $368.6 \mathrm{~m} 2 / \mathrm{g}$ with a total pore volume = $0.4166 \mathrm{ml} / \mathrm{g}$; Gel permeation chromatography (GPC) (Fig. 5), polystyrene standards (Mw 1000-1000000 $\mathrm{g}$ mol-1): $M n=11400, M w=19400 \mathrm{~g} / \mathrm{mol}$. The TGA analysis (Fig. 6) of that polymer was the initial weight loss due to thermal degradation commencing at $\sim 377.53^{\circ} \mathrm{C}$ with an $1.28 \%$ loss of mass.
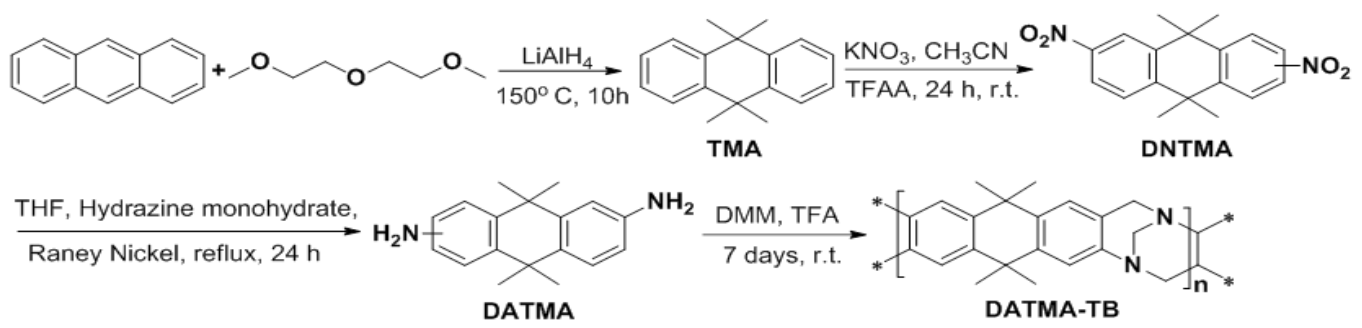

Scheme 1: synthesis of 2, 6(7)-Diamino-9,9,10,10-tetramethyl-9,10-dihydroanthracene-Tröger base polymer (DATMA-TB)

\section{RESULTS AND DISCUSSION}

A TMA is synthesised by alkylation of anthracene, with a lower yield. This low yield can be attributed to several products of alkyl anthracene which were formed, $30 \%$ of which was tetramethyl. This alkylation process occurs with $\mathrm{LiAlH}_{4}$ as a reducing agent to react with diglyme to form an intermediate from a methyl carbonium ion to attack the active positions of anthracene. A DNTMA is synthesised by nitration of TMA, which forms mixed compounds of the 2,6 and 2,7 dinitro position. Potassium nitrate and the trifluoroacetic anhydride were used to form the nitrating agent trifluoroacetyl nitrate, potassium nitrate being chosen because it is the least hydroscopic compared with other common nitrates while the nitric acid produces nitro compound multiproducts. This method affords a good product yield with small quantities of impurities which were easily separated. The nitration was carried out in 
acetonitrile solvent because of the greater solubility of the inorganic salts. The reaction was processed at room temperature because increased heating will result in a higher ratio of impurity. The crude product was subjected to column chromatography (eluent: Chloroform) to produce as an off-white powder. The FTIR of DNTMA appears as asymmetric and symmetric stretching of $\mathrm{NO}_{2} 1516$ and $1346 \mathrm{~cm}^{-1}$, respectively. The ${ }^{13} \mathrm{C}$ NMR of DNTMA refers to $\mathrm{C}_{\text {aromatic }}-\mathrm{NO}_{2}$ at $\delta 148.0$ and 147.0. The reduction of DNTMA to DATMA using hydrazine monohydrate and a catalytic quantity of Raney nickel produced amines with the highest purity. The reduction was carried out under reflux to decrease the reaction time. The reduction must be conducted under an inert atmosphere using solvents that have been thoroughly deoxygenated. The FTIR of DATMA appears as asymmetric and symmetric stretching of the $\mathrm{NH}_{2}$ group at $3340 \& 3309 \mathrm{~cm}^{-1}$, respectively, with bending vibration of the $\mathrm{NH}_{2}$ group at $1620 \mathrm{~cm}^{-1}$. The ${ }^{1} \mathrm{H}$ NMR of DATMA refers to the $\mathrm{NH}_{2}$ group at $\delta$ $3.59 \mathrm{ppm}$. The ${ }^{13} \mathrm{C}$ NMR of DATMA refers to $\mathrm{C}_{\text {aromatic }}{ }^{-}$ $\mathrm{NH}_{2}$ at 145.3 and $143.1 \mathrm{ppm}$. The DATMA monomer was polymerised using dimethoxymethane (DMM) which is a "methylene" source in a strongly acidic solvent, and a catalyst such as trifluoroacetic acid (TFA). A typical procedure of polymerisation is one equivalent of a pure aromatic diamine mixed with five equivalents of dimethoxymethane (excess) and cooled to the temperature of ice. TFA (8-10 ml per gram of monomer) is then slowly added drop-wise over a period of 10 to 30 minutes. The polymerisation mixture is stirred at room temperature under a constant inert atmosphere until the solution realises the required viscosity. The colour of the solution will change to dark red. Tröger base polymerisation exhibits the rate of acid addition and changes in concentration. To quench it, the mixture is slowly poured into aqueous ammonium hydroxide solution to precipitate the polymer as an amorphous solid. The FT-IR of polymer (Fig. 1) shows disappearing vibration stretching and bending of $-\mathrm{NH}_{2}$ and the appearance of a new vibration of $\mathrm{C}_{\text {aliphatic }}-\mathrm{N}$ for Trögerbase cyclic. ${ }^{1} \mathrm{H}$ NMR (Fig. 2) clearly refers to Ar-N$\mathrm{CH}_{2}$ for Tröger-base cyclic at $\delta 4.48$ and $3.90 \mathrm{ppm}$ beside to $\mathrm{N}-\mathrm{CH}_{2}-\mathrm{N}$ at $\delta 4.27$ ppm. ${ }^{13} \mathrm{C} \mathrm{NMR} \mathrm{(Fig.} \mathrm{3)}$ of polymer refers to $\mathrm{C}_{\text {aromatic }} \mathrm{N}$ at $\delta 146.9$ and 144.5 $\mathrm{ppm}$ and $\mathrm{C}_{\text {aliphatic }}-\mathrm{N}$ at $\delta 67.4$ and $64.24 \mathrm{ppm}$. The solubility of that polymer is shown as good in DMSO, DMAC, NMP, DMF, DCM and $\mathrm{CHCl}_{3}$ but insoluble in Toluene, Xylene, THF, ethanol and acetone (Table 1). The BET surface area calculated from nitrogen isotherms shows microporosity of DATMATB polymer where the BET surface area is 368.6 $\mathrm{m}^{2} / \mathrm{g}$, the total pore volume $=0.4166 \mathrm{ml} / \mathrm{g}$, which is attributed to methyl groups besides the heterocyclic $V$ shape of the Tröger base BET surface area (Fig. 4). Gel permeation chromatography (GPC) (Fig. 5) polystyrene standards (Mw 1000-1000000 $\left.\mathrm{g} \mathrm{mol}^{-1}\right) M n=11400, M w=19400 \mathrm{~g} / \mathrm{mol}$. Thermal gravimetric analysis (TGA) of the DATMA-TB polymer showed an initial weight loss due to thermal degradation commencing at $\sim 377^{\circ} \mathrm{C}$ with a $1.28 \%$ loss of mass, then a decrease in mass until a loss of $\sim 47 \%$ at $\sim 631^{\circ} \mathrm{C}$ where complete decomposition took place (Fig. 6).

Table 1: Solubility of DATMA-TB in common organic solvents

\begin{tabular}{|c|c|c|c|c|c|c|c|c|c|c|}
\hline \multicolumn{11}{|c|}{ Solvents ${ }^{1, l l}$} \\
\hline & DMSO & DMAC & NMP & DMF & Toluene Xylene & THF & Acetone & DCM & $\mathrm{CHCl} 3$ & EtOH \\
\hline DATMA-TB & + & + & + & + & $-\quad \quad-$ & - & - & + & + & - \\
\hline
\end{tabular}

'Solubility guide: (+) soluble, (-) insoluble. "All solvents tested had a concentration of $0.01 \mathrm{~g} \mathrm{ml}^{-1}$ at room temperature

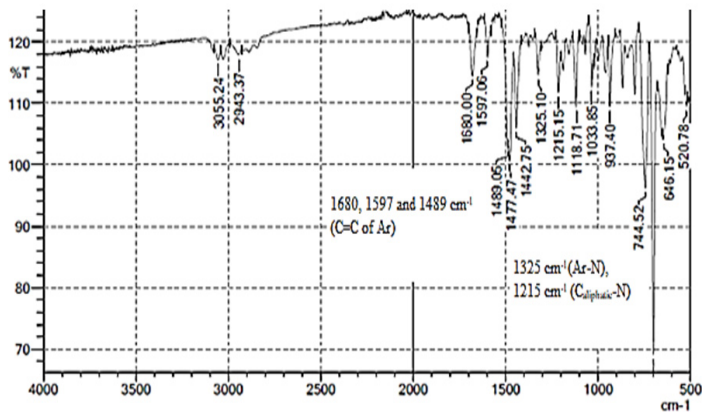

Fig. 1. FTIR of DATMA-TB

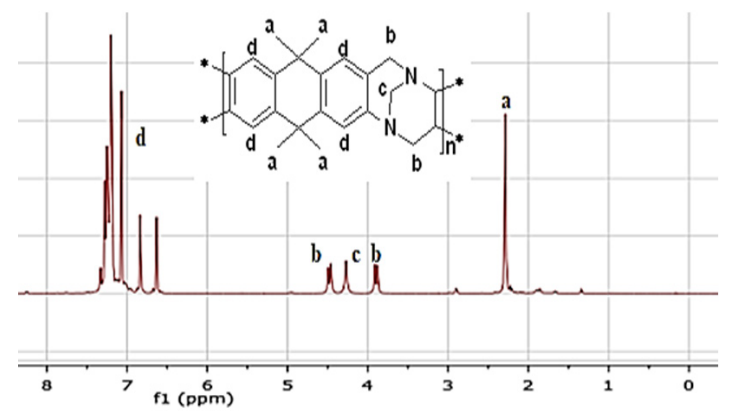

Fig. 2. ${ }^{1} \mathrm{H}$ NMR of DATMA-TB 


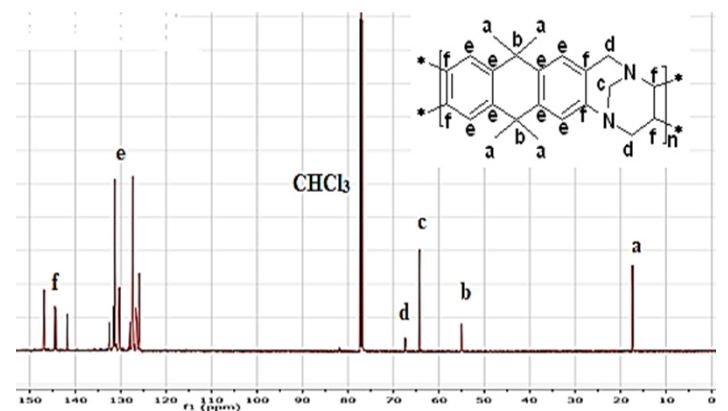

Fig. 3. ${ }^{13} \mathrm{C}$ NMR of DATMA-TB

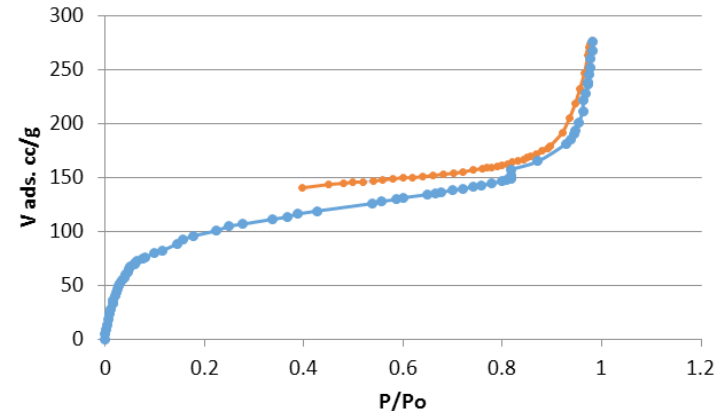

Fig. 4. Nitrogen adsorption isotherms at $77 \mathrm{~K}$ for DATMA-TB

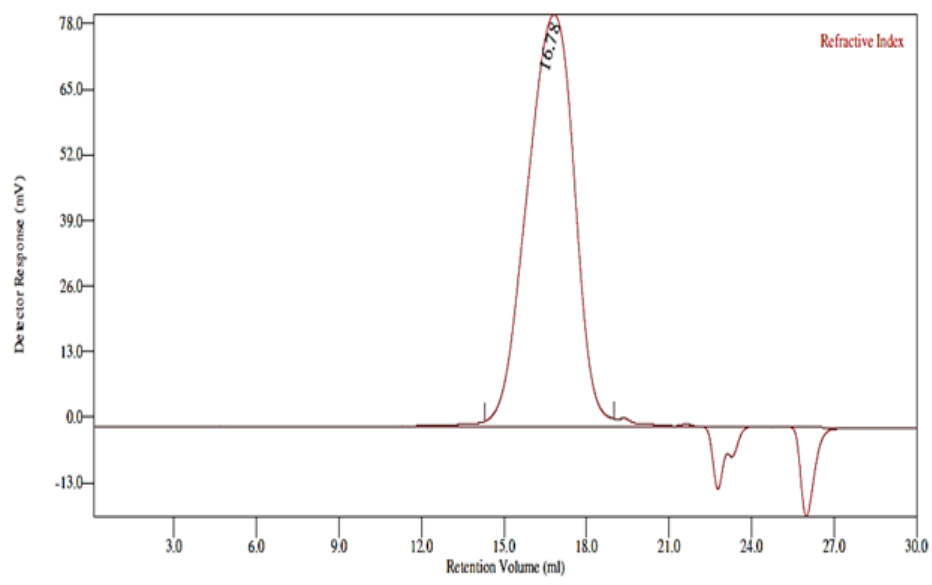

\begin{tabular}{|l|r|}
\hline Peak RV - (ml) & 16,783 \\
\hline Mn - (Daltons) & 11,406 \\
\hline Mw - (Daltons) & 19,446 \\
\hline Mz - (Daltons) & 32,796 \\
\hline Mp - (Daltons) & 13,014 \\
\hline Mw / Mn & 1,705 \\
\hline Percent Above Mw: 0 & 100,000 \\
\hline Percent Below Mw: 0 & 0,000 \\
\hline Mw 10.0\% Low & 4,408 \\
\hline Mw 10.0\% High & 56,835 \\
\hline Wt Fr (Peak) & 1,000 \\
\hline RI Area - (mvml) & 162,36 \\
\hline UV Area - (mvml) & 0.00 \\
\hline
\end{tabular}

Fig. 5. GPC (based on polystyrene standards) for DATMA-TB

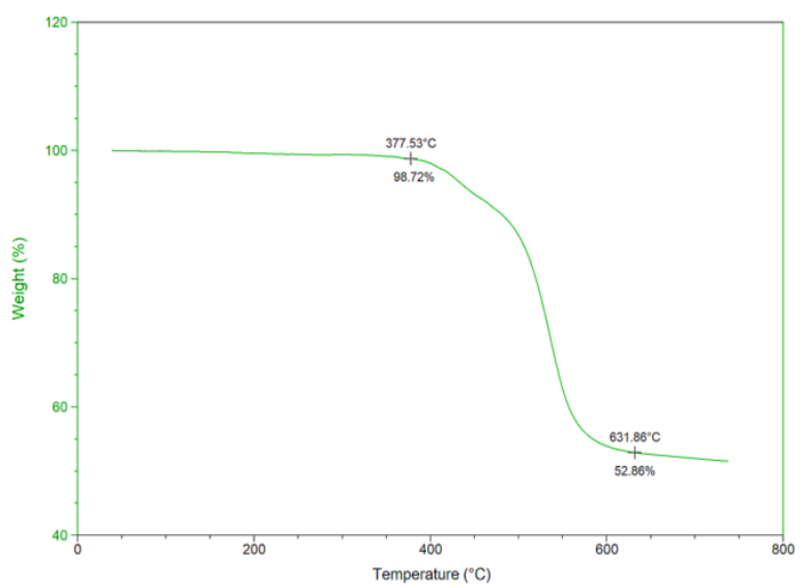

Fig. 6. Thermal gravimetric analysis for DATMA-TB

\section{CONCLUSION}

In summary, TMA synthesis by alkylating anthracene took place with a $30 \%$ yield following nitration to produce DNTMA $60 \%$, the DATMA resulting in $90 \%$. DATMA-Tröger base polymer was produced as white by condensation polymerisation of DATMA with DMM in TFA. TMA, DNTMA and DAMTA compounds are characterised by FT-IR, ${ }^{1} \mathrm{H}-\mathrm{NMR}$, ${ }^{13} \mathrm{C}-\mathrm{NMR}$ besides TGA and the BET surface area of polymer.

\section{REFERENCES}

1. Tröger, J. J. für Praktische Chemie., 1887, 2. Spielman, M. A.; J. Am. Chem. Soc., 1935, $36,225-245$. 
3. Larson, S. B.; Wilcox; C. S., Acta Cryst. Section C., 1986, 42, 224-227.

4. Vögtle, F., Fascinating Molecules in Organic Chemistry; Wiley and Sons., 1992, 237-249.

5. Becker D. P.; Finnegan P. M.; Collins P. W.; Tetrahedron Letter., 1993, 34, 1889-1892.

6. Adrian, J. C.;Wilcox C. S.; J.Am. Chem. Soc., 1992, 114, 1398-1403.

7. Weber, E.; Müller, U.; Worsch, D.; Vögtle, F.; Will, G.; Kirfel, A. ; J. Chem. Soc. Chem. Comm., 1985, 1578-1580.

8. Sergeyev, S. Helv. Chim. Acta., 2009, 92, 415-444.

9. Adrian, J. C. , Wilcox, C. S. ; J. Am. Chem. Soc., 1989, 111, 8055-8057.

10. Wilcox, C.S.; Cowart, M. D. ; Tetrahedron Letters., 1986, 27, 5563-5566.

11. Didier, D.; Tylleman, B.; Lambert N.; Velde, C.; Blockhuys F.; Collas A.; Sergeyev S. Tetrahedron., 2008, 64, 6252-6262.

12. Trapp, O.; Schurig V. J. Am. Chem. Soc., 2000, 122, 1424-1430.

13. Carta, M.; Croad M.; McKeown N. B., 2010, WO2012/035328 A1.

14. Carta, M.; Malpass-Evans, R.; Croad, M.; Rogan, Y.; Jansen J. C.; Bernardo P.; Bazzarelli, F; McKeown N. B. Science., 2013, 339, 303-307.

15. Carta M.; Croad M.; Malpass-Evans R.; Jansen J. C.; Bernardo P.; Clarizia,G.; Lanc,
K. ; McKeown N. B. Adv. Mater., 2014, 26, 3526-3531.

16. Rose I.; Carta M.; Malpass-Evans R.; Ferrari M.; Bernardo P.; Clarizia G.; Jansen J. C.; McKeown, N. B. ACS Macro Letters., 2015, 4, 912-915.

17. Z. G. Wang, X. Liu, D. Wang and J. Jin, Poly. Chem., 2014, 5, 2793-2800.

18. ZhuangY:; Seong, J.G.; Do, Y.S.; Lee, W.H.; Lee, M. J.; Cui, Z.; Lozano, A. E.; Guiver, M. D.; Lee, Y. M. Chem. Comm., 2016, 52, 3817-3820.

19. Ghanem, B.; Alaslai N.; Miao, X.; Pinnau I.; Polymer., 2016, 96, 13-19.

20. Karim S. A.; Braihi A. J. JGPT., 2017, 12(9), 30-35.

21. Carta M.; Croad; M.; Bugler K.; Masyib, K. J; McKeown N. B. Polym. Chem., 2014, 5, 5262-5266.

22. Rong Y.; Malpass-Evans R.; Carta M.; McKeown, N. B.; Attard G. A.; Marken, F. Electroanalysis., 2014, 26, 904-909.

23. Cabrero-Antonino J. R.; García T.; RubioMarqués P.; Vidal-Moya J. A.; Leyva-Pérez A.; Al-Deyab S. S.; Al-Resayes S. I.; Díaz U.; Corma A. ACS Catal., 2011, 1, 147-158.

24. Poli E.; Merino E.; Diaz U.; Brunel, D.; Corma A. J. Phys. Chem. C., 2011, 115, 7573-7585.

25. Li W.; Michinobu T. Macromol. Chem. and Phys., 2016, 217, 863-870.

26. Kamatani J.; Takiguchi T.; Okada S. US Patent Application., 2008, 20080007161. 